\title{
Reversing acute bronchoconstriction in asthma: the effect of bronchodilator tolerance after treatment with formoterol
}

\author{
S.L. Jones*, J.O. Cowan*, E.M. Flannery*, R.J. Hancox*, G.P. Herbison*, D.R. Taylor*
}

\begin{abstract}
Reversing acute bronchoconstriction in asthma: the effect of bronchodilator tolerance after treatment with formoterol. S. L. Jones, J.O. Cowan, E. M. Flannery, R. J. Hancox, G.P. Herbison, D.R. Taylor. C) ERS Journals Ltd 2001.

ABSTRACT: Continuous treatment with a short-acting $\beta_{2}$-agonist can lead to reduced bronchodilator responsiveness during acute bronchoconstriction. This study evaluated bronchodilator tolerance to salbutamol following regular treatment with a long-acting $\beta_{2}$-agonist, formoterol. The modifying effect of intravenous corticosteroid was also studied.

Ten asthmatic subjects (using inhaled steroids) participated in a randomised, doubleblind, placebo-controlled, cross-over study. Formoterol $12 \mu \mathrm{g}$ b.i.d. or matching placebo was given for 10-14 days with $>2$ weeks washout. Following each treatment, patients underwent a methacholine challenge to induce a fall in forced expired volume in one second (FEV1) of at least $20 \%$, then salbutamol $100 \mu \mathrm{g}, 100 \mu \mathrm{g}$, and $200 \mu \mathrm{g}$ was inhaled via a spacer at $5 \mathrm{~min}$ intervals, with a further $400 \mu \mathrm{g}$ at $45 \mathrm{~min}$. After a third singleblind formoterol treatment period, hydrocortisone $200 \mathrm{mg}$ was given intravenously prior to salbutamol. Dose-response curves for change in FEV1 with salbutamol were compared using analysis of covariance to take account of methacholine-induced changes in spirometry.

Regular formoterol resulted in a significantly lower FEV1 after salbutamol at each time point compared to placebo $(p<0.01)$. The area under the curves (AUCs) for 15 (AUCo-15) and $45(\mathrm{AUC0}-45) \mathrm{min}$ were $28.8 \%$ and $29.5 \%$ lower following formoterol treatment $(\mathrm{p}<0.001)$. Pretreatment with hydrocortisone had no significant modifying effect within $2 \mathrm{~h}$ of administration.

It is concluded that significant tolerance to the bronchodilator effects of inhaled salbutamol occurs $36 \mathrm{~h}$ after stopping the regular administration of formoterol. This bronchodilator tolerance is evident in circumstances of acute bronchconstriction. Eur Respir J 2001; 17: 368-373.
\end{abstract}

*Depts of Medical and Surgical Sciences and "Preventive and Social Medicine, Dunedin School of Medicine, University of Otago, Dunedin, New Zealand

Correspondence: D.R. Taylor Dunedin School of Medicine, University of Otago, Dunedin, New Zealand

Fax: + 6434747641

Keywords: formoterol

long acting beta-agonist

tolerance

Received: March 132000

Accepted after revision August 182000

This work was supported in part, by a GlaxoWellcome Research Fellowship, awarded to S.L. Jones.
Current guidelines for the management of chronic asthma propose that long-acting $\beta$-agonists such as salmeterol and formoterol should be added to antiinflammatory treatment for the control of persistent or breakthrough symptoms $[1,2]$. This strategy appears to be beneficial not only in controlling symptoms [3-7], but also in reducing the frequency of asthma exacerbations during long-term treatment $[8,9]$.

Despite these positive outcomes, against a background of concern about the safety of $\beta$-agonists [10] significant attention has been given to the issue of $\beta$ adrenoceptor down-regulation and the advent of drug tolerance. A number of studies using salmeterol and formoterol have been conducted to investigate this issue. These have shown that during treatment with long-acting agents, tolerance to the protective effects of $\beta$-agonists against exercise-induced bronchospasm [11] and nonspecific bronchoconstrictors is easily demonstrated [12] and develops rapidly [13]. Concurrent treatment with inhaled corticosteroid does not appear to modify these effects [14-17], although corticosteroids may be used acutely to reverse them $[18,19]$.
In contrast, evidence for the development of bronchodilator tolerance has been less clear cut. In the majority of studies, no evidence of impaired bronchodilator responsiveness has been found [20-24], although in some investigations a reduction in bronchodilator response has been reported [18, 25, 26]. However, a major drawback in the design of these studies is that most have been carried out in patients with stable asthma, in whom a reduction in $\beta_{2^{-}}$ adrenoceptor function may be relatively unimportant in maintaining adequate bronchomotor tone. This contrasts with patients with acute asthma.

Recently, using a simple but novel approach, the authors have demonstrated that after six weeks regular treatment with the short-acting $\beta_{2}$-agonist terbutaline, the bronchodilator response to salbutamol is significantly reduced in circumstances of acute bronchoconstriction [27]. This is more relevant in determining the clinical importance of tolerance. The present study has extended this approach to assess the development of bronchodilator tolerance during regular treatment with the long-acting $\beta$-agonist formoterol. The study was 
also designed to confirm whether administering systemic corticosteroid rapidly reverses any observed effect.

\section{Methods}

\section{Subjects}

Volunteers aged $18-70$ yrs, with a history of mild to moderate asthma, were invited to participate in the study. All had a positive methacholine challenge (provocative dose causing a $20 \%$ fall in forced expiratory volume in 1 second (FEV1) of less than $8 \mu \mathrm{mol}$ (PD20)) within 2 months of recruitment. All were receiving maintenance inhaled corticosteroid treatment with no change in dose or other asthma treatment during the 6 weeks prior to enrolment. All those receiving oral or high dose inhaled corticosteroids ( $>2000 \mu \mathrm{g} \cdot \mathrm{day}^{-1}$ of beclomethasone or equivalent) were excluded, as were patients receiving maintenance inhaled long-acting $\beta_{2}$-agonists. Current or previously heavy cigarette ( $>5$ pack years) smokers were also excluded.

\section{Study design}

All patients entered a 2-week run-in phase during which control of asthma was assessed by means of a daily record card in which patients entered morning and evening peak flows and symptom scores. Throughout the study patients were maintained on their usual dose of inhaled steroids. All $\beta_{2}$-agonists were stopped and patients were provided with ipratropium bromide $40 \mu \mathrm{g} \cdot$ puff $^{-1}$ (Boehringer, Ingelheim, Germany) for "as required" use. Patients with unstable asthma, or who were unable to obtain adequate relief of breakthrough symptoms using inhaled ipratropium bromide during the run-in, were withdrawn from the study. All other patients then received each of the first two study treatments according to a randomised, double-blind, crossover design. The treatments were formoterol (Foradil, Novartis, Basel, Switzerland) $12 \mu \mathrm{g}$ twice daily administered as dry powder via an aeroliser for $7-10$ days, and matching placebo containing lactose. There was a washout period of at least 2 weeks between each of the first two treatments. Following a further 2 week washout interval, patients proceeded into a third treatment period during which formoterol $12 \mu \mathrm{g}$ twice daily was administered single-blind (patient) for 7-10 days. This was to permit a subsequent assessment of the effect of intravenous hydrocortisone on the bronchodilator dose-response.

\section{Study visits and measurements}

Patients visited the research laboratory at the completion of each of the three treatment periods. Study medications and inhaled ipratropium were withheld for at least 36 and $6 \mathrm{~h}$ respectively. On each occasion, and prior to any measurements being obtained, a venous cannula was inserted into a forearm vein, and either normal saline (following each of the first two treatment arms) or hydrocortisone $200 \mathrm{mg}$ (following the third treatment arm, formoterol $12 \mu \mathrm{g}$ b.i.d.) was given single-blind (patient) intravenously. The administration of steroid $1 \mathrm{~h}$ before measuring the dose-response to salbutamol was to mimic what might occur during an acute episode of asthma. Active hydrocortisone was given during the last of the three treatment periods to avoid any steroid-related carry over effect on $\beta$-adrenoceptor function.

Exactly $1 \mathrm{~h}$ later, patients underwent a methacholine challenge followed by a bronchodilator response measurement. The methacholine challenge was performed using a modified version of the rapid challenge procedure [28]. After measurement of baseline FEV1 according to American Thoracic Society (ATS) criteria [29] using a rolling seal spirometer (Spirotech, Graseby, Georgia, USA), increasing doses $(0.044-45 \mu \mathrm{mol})$ of methacholine were administered by nebuliser, controlled by a Morgan Nebicheck dosimeter (Morgan, Gillingham, Kent, UK). The procedure was stopped after the FEV1 had fallen by $\geqslant 20 \%$. The PD20 was calculated by linear interpolation.

Immediately after the PD20 had been reached, an abbreviated dose-response test to inhaled salbutamol (Ventolin, GlaxoWellcome, Greenford, UK) was undertaken. The salbutamol was administered from a metered dose inhaler via a large volume spacer (Volumatic, GlaxoWelcome, Greenford, UK). Doses of $100 \mu \mathrm{g}, 100 \mu \mathrm{g}$, and $200 \mu \mathrm{g}$ were given at 0,5 , and $10 \mathrm{~min}$, respectively. Spirometry was performed immediately prior to each dose, and also at 15, 30 and 45 min.

A further $400 \mu \mathrm{g}$ of salbutamol was administered at $45 \mathrm{~min}$ to maximise bronchodilatation prior to further spirometry and a second methacholine challenge at $60 \mathrm{~min}$, using the same method as previously. The aim of this further challenge was to measure the protective effect of the salbutamol against further methacholine. Once a PD20 had been established for the second methacholine challenge, patients were given inhaled salbutamol ad lib and remained in the research laboratory until their FEV1 had returned to at least $90 \%$ of baseline.

\section{Analysis of results}

The primary study end-point was area under the curve (AUC) for change in FEV1 following inhaled salbutamol. From a previous investigation [27], the sample size was calculated so that there was $90 \%$ power to detect a $30 \%$ difference in AUC with a significance of 0.05 . Analyses were undertaken to assess treatmentrelated differences, as well as the effects of intravenous hydrocortisone. Analyses of covariance were performed to take into account any differences in the baseline FEV1, the fall in FEV1 during the methacholine challenge and log PD20 methacholine. Where PD20 was not achieved after the highest dose of methacholine, an arbitrary value of $64 \mu \mathrm{mol}$ was assigned. The increase in FEV1 after each dose of salbutamol, expressed as a percentage of the fall from baseline during the methacholine challenge, was also analysed. 
Further comparisons were made for post-salbutamol PD20 values to assess treatment-related differences in the protective effect given by inhaled salbutamol against methacholine-induced bronchoconstriction. When comparing differences in the post-salbutamol PD20s between the first two treatment arms, the presalbutamol PD20 was used as a covariate.

\section{Ethical considerations}

Asthma control was carefully monitored throughout the study. Each patient had an individualised asthma action plan, a supply of prednisone and an inhaled $\beta_{2^{-}}$ agonist for emergency use, and $24 \mathrm{~h}$ access to one of the study investigators, in case of an acute exacerbation. The study was approved by the Otago Ethics Committee. Each patient gave written informed consent.

\section{Results}

Twelve patients were enrolled into the study. Two patients withdrew following the run-in; one was unable to tolerate ipratropium as relief medication, the other developed diabetes mellitus. The ten randomised patients ( 9 female, aged $18-65$ years) had a mean (95\% confidence interval (CI)) FEV1\% predicted of $95.1 \%(82.9-107.3)$ on entry into the study. Their median (range) dose of inhaled corticosteroid was $800 \mu \mathrm{g} \cdot \mathrm{day}^{-1}(200-2000 \mu \mathrm{g})$ of beclomethasone or equivalent. One patient withdrew between the second and third treatment periods due to unstable asthma. Thus nine patients completed all three treatment arms of the study. Compliance with study medication was greater than $90 \%$ during each of the treatment arms.

\section{Baseline lung function and bronchial hyper-responsiveness}

Baseline FEV1 and mean methacholine PD20 values were not significantly different following each of the three treatment periods. The mean percentage fall in FEV1 did not differ between the treatments (table 1).

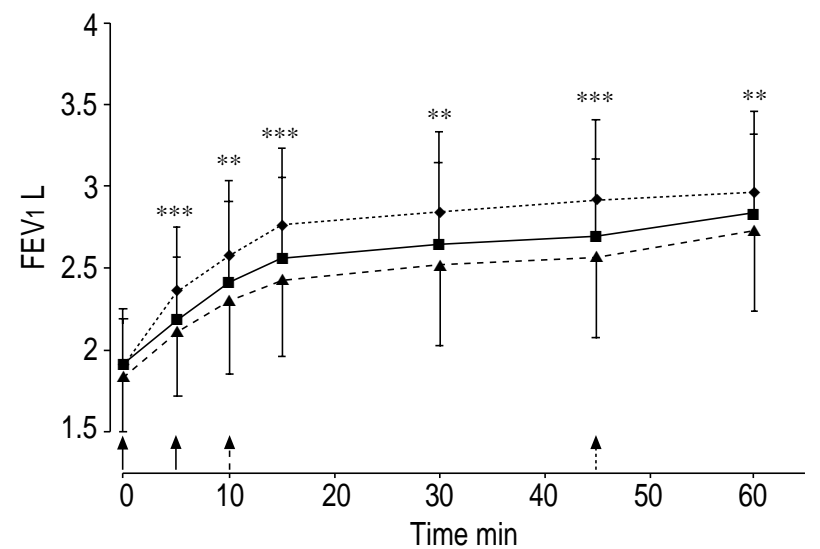

Fig. 1. - Forced expired volume in one second (FEV1) following the administration of salbutamol at $0,5,10$ and 45 min. $\$$ : Placebo; $\mathbf{\square}$ : Formoterol; $\boldsymbol{\Delta}$ : Formoterol plus hydrocortisone. 4 : $100 \mu \mathrm{g}$ salbutamol; : $200 \mu \mathrm{g}$ salbutamol; : $400 \mu \mathrm{g}$ salbutamol. **: $\mathrm{p}<0.01, * * *: \mathrm{p}<0.001$ for formoterol versius placebo comparisons.

\section{Dose-response curves to salbutamol}

Mean FEV1 at each time point following salbutamol administration is shown in figure 1 . The values were significantly lower with formoterol treatment than placebo at each time point. Dose-response curves following salbutamol, expressed as a percentage of the fall in FEV1 from the pre-methacholine baseline, are shown in figure 2. Prior treatment with formoterol was associated with a significantly smaller increase at each time point. AUC $0-15$ and $\mathrm{AUC}_{0}-45$ were $28.8 \%$ and $29.5 \%$ lower following treatment with formoterol than placebo at each time point $(\mathrm{p}<0.0004$ and $\mathrm{p}<0.0001$, respectively). Prior administration of hydrocortisone did not result in any significant difference compared to formoterol alone for either FEV1 at each time point, or AUC0-15 and $\mathrm{AUC}_{0}-45$, although the difference compared to placebo was significant.

\section{Bronchoprotective effect of salbutamol}

Baseline FEV1 prior to the second methacholine challenge was significantly lower following the formoterol treatment arm than placebo $(\mathrm{p}=0.01)$ (table 1). The protective effect of salbutamol as

Table 1.-Baseline lung function and bronchial hyperresponsiveness, area under curves (AUC) for dose-response to salbutamol, and post-salbutamol bronchial hyperresponsiveness after each treatment period.

\begin{tabular}{lccc}
\hline & Placebo & Formoterol & $\begin{array}{c}\text { Formoterol plus } \\
\text { hydrocortisone }\end{array}$ \\
\hline Subjects n & 10 & 10 & 9 \\
Baseline FEV1 L & $2.59(2.16-3.02)$ & $2.59(2.14-3.04)$ & $2.45(2.02-2.88)$ \\
PD20 for first methacholine challenge $\mu \mathrm{mol}$ & $2.12(0.57-3.67)$ & $1.57(0.34-2.80)$ & $3.43(0.31-6.55)$ \\
FEV1 fall from baseline \% & $25.91(22.44-29.38)$ & $25.81(21.99-29.63)$ & $25.35(22.51-28.19)$ \\
AUC0-15 & $7.72(6.84-8.60)$ & $5.49(4.61-6.37)$ & $5.56(4.09-7.05)$ \\
AUC0-45 & $35.36(30.03-40.68)$ & $24.94(19.62-30.26)$ & $27.06(20.38-33.75)$ \\
FEV1 before second methacholine challenge & $2.97(2.81-3.13)$ & $2.84(2.68-3.00)$ & $2.84(2.57-3.11)$ \\
PD20 for methacholine challenge after & & & \\
$\quad$ salbutamol $\mu$ mol & $23.19(8.94-37.44)$ & $12.12(2.89-21.35)$ & $19.30(2.31-36.29)$ \\
\hline
\end{tabular}

Results reported as mean (95\% confidence interval). PD20: Provocative dose causing a $\geqslant 20 \%$ fall in forced expired volume in one second (FEV1). 


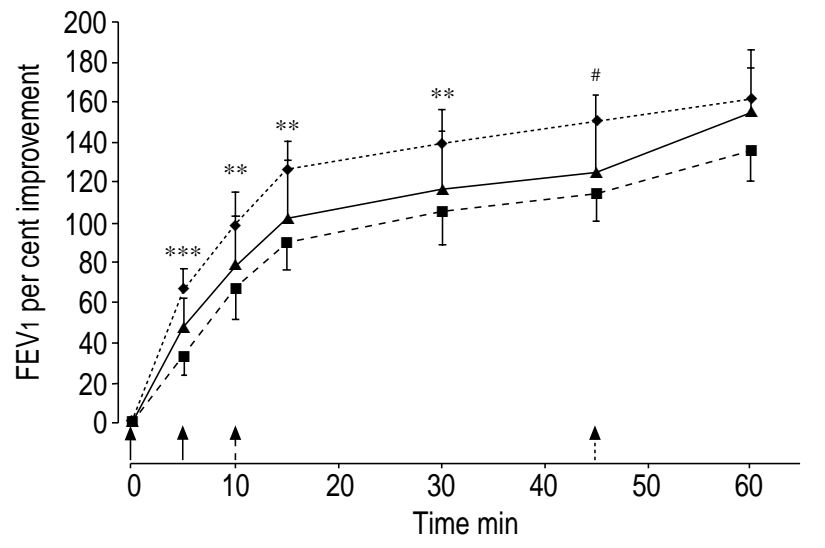

Fig. 2. - Changes in forced expired volume in one second (FEV1) expressed as a percentage of the fall in FEV1 following methacholine challenge following the administration of salbutamol at 0,5 , 10 and 45 min. $\$$ : Placebo; $\mathbf{\square}$ : Formoterol; $\boldsymbol{\Delta}$ : Formoterol plus hydrocortisone. $4: 100 \mu \mathrm{g}$ salbutamol; : $200 \mu \mathrm{g}$ salbutamol; $400 \mu \mathrm{g}$ salbutamol. **: $\mathrm{p}<0.01, * * *: \mathrm{p}^{1}<0.001$, \#: $\mathrm{p}<0.002$ fờ formoterol versus placebo comparisons.

measured by the increase in methacholine PD20 from baseline and expressed as doubling dose concentrations (d.d.s) was 2.74 d.d.s (95\% C.I. 2.19-3.29) following formoterol and 3.97 d.d.s (95\% C.I. $3.42-4.52)$ following placebo $(\mathrm{p}<0.01)$. Following formoterol with hydrocortisone the increase in PD20 was 2.62 d.d.s $(95 \%$ C.I. $2.01-3.23)(\mathrm{p}=0.79$ for comparison with formoterol alone).

\section{Discussion}

The results of the present study show that in patients with mild to moderate asthma requiring maintenance inhaled steroid therapy, tolerance to the bronchodilator effect of salbutamol may be demonstrated in the presence of acute bronchoconstriction (mean fall in FEV1 26\%) following treatment with regular formoterol. After salbutamol administration, the mean FEV1 was significantly lower at all time points and the AUC $0-15$ for change in FEV1 was reduced by $28.8 \%$ with regular formoterol compared to placebo. The magnitude of these changes is similar to what has previously been reported in a study using regular terbutaline [27]. In that investigation the $\mathrm{AUC} 0-15$ for FEV1 was reduced by $36.0 \%$. Thus the present results confirm that bronchodilator tolerance develops during regular $\beta$-agonist treatment irrespective of whether a long or short-acting agent is being used.

The findings provide evidence that the effects of bronchodilator tolerance are more likely to be encountered when patients are experiencing bronchospasm. Most recent studies have failed to demonstrate bronchodilator tolerance with long-acting $\beta$-agonists $[20-24]$. This may be because these investigations have included patients whose asthma is stable and in whom there was no significant bronchoconstriction. For this reason, the validity of these earlier results is questionable. It is difficult to appropriately conduct controlled bronchodilator response studies in patients with unstable asthma. It was in an attempt to address this issue that mild airway obstruction was induced in the patients using a nonspecific bronchoconstrictor. Although the present model does not accurately mimic acute severe asthma, in which other factors besides $\beta$-adrenoceptor down-regulation, induced by continuous $\beta$-agonist therapy, may impair the response to inhaled bronchodilator, it does permit the conclusion that bronchodilator tolerance is more likely to be important in the presence of bronchoconstriction.

The study design included a $36 \mathrm{~h}$ period of drug withdrawal prior to testing for bronchodilator tolerance. If anything, this may have resulted in a diminution in the magnitude of the effect that was found, given that the status of $\beta$-adrenoceptors may change rapidly [30]. It might also be argued that testing for bronchodilator tolerance without a period of drug withdrawal would have been more clinically relevant. The principal reason for not doing so was to avoid the problem of functional antagonism to methacholine which would have resulted from the continuing action of formoterol. This would have had the potential to make acute bronchoconstriction, upon which demonstrating the development of tolerance was dependent, more difficult to achieve.

At $45 \mathrm{~min}$ our patients received a further $400 \mu \mathrm{g}$ of salbutamol (making a total of $8 \times 100 \mu \mathrm{g}$ puffs) in order to induce maximal bronchodilatation. Following this, a significantly greater increase in FEV1 was achieved following formoterol treatment when compared to placebo (139 and $58 \mathrm{~mL}$, respectively, $\mathrm{p}<0.02)$. This indicates that at that time point, even though baseline FEV1 had been recovered, residual bronchoconstriction was still present following formoterol treatment, despite the fact that the patients had already received $400 \mu \mathrm{g}(4$ puffs) of salbutamol. Thus, as might have been anticipated, overcoming the effects of $\beta$-adrenoceptor tolerance required the use of higher doses of salbutamol, although there is evidence that this may not always be successful [31]. This suggests that, in circumstances of acute bronchoconstriction, patients taking long-acting $\beta$-agonists may require higher doses of "reliever" short-acting $\beta$-agonist in order to obtain maximum bronchodilatation.

The clinical importance of this is unclear. No studies have been carried out to examine the exact relationship between $\beta$-adrenoceptor tolerance and asthma control during long-term treatment with $\beta$-agonists. Nor is it known whether individual susceptibility to the development of tolerance influences how patients respond to treatment during acute life-threatening episodes. However, the results of other studies offer indirect but reassuring evidence. The frequency of asthma exacerbations is reduced with regular long-acting $\beta$-agonist, not increased $[8,9]$. Furthermore, in a controlled study, changes in symptoms and peak flow rates during the early phases of an exacerbation do not appear to be different in patients receiving regular formoterol from those who are not [32]. In addition, the bronchodilator response to very high doses of nebulised salbutamol, such as would be used to treat acute severe asthma in an emergency department, is no different between patients taking or not taking regular salmeterol [33].

In the present study, prior administration of intravenous hydrocortisone $1 \mathrm{~h}$ before inducing 
bronchoconstriction and giving salbutamol had no significant effect on the magnitude of bronchodilator tolerance. Even when an additional $400 \mu \mathrm{g}$ of salbutamol was administered at $45 \mathrm{~min}$ i.e. $1 \mathrm{~h}$ and $45 \mathrm{~min}$ after giving hydrocortisone, the corticosteroid had no effect on the magnitude of the increase in FEV1 during the subsequent $15 \mathrm{~min}$. This outcome is in apparent contrast to the report by TAN et al. [18], in which the combined use of both oral prednisone and intravenous hydrocortisone reversed bronchodilator tolerance to formoterol. However, in the present study patients were followed for only $2 \mathrm{~h}$ after giving corticosteroid, whereas TAN et al. [18] followed their patients for $8 \mathrm{~h}$. Taken together, these results confirm that although giving corticosteroid is likely to be effective in reversing the effects of $\beta$-adrenoceptor tolerance, it cannot be relied upon to do so in the early phases of an acute episode of asthma.

In conclusion, this study has demonstrated that significant tolerance to the bronchodilator effects of inhaled salbutamol occurs $36 \mathrm{~h}$ after cessation of formoterol. This effect is likely to be more important in circumstances of acute bronchconstriction. Whether or not this effect increases with increasingly severe airway obstruction, or is accentuated when patients take excessive amounts of $\beta$-agonist, requires to be evaluated further.

Acknowledgements. The authors wish to thank the volunteers who participated in this study and Boehringer Ingelheim for supplies of Atrovent.

\section{References}

1. British Thoracic Society. Guidelines on asthma management. Thorax 1997; 52: Suppl. 1.

2. NHLBI. Guidelines for the diagnosis and management of asthma 1997. Expert Panel Report. NIH Publication $97-4051$.

3. Greening AP, Ind PW, Northfield M, Shaw G. Added salmeterol versus higher dose corticosteroid in asthma patients with symptoms on existing inhaled corticosteroid. Lancet 1995; 344: 219-224.

4. Woolcock A, Lundback B, Ringdal N, Jacques LA. Comparison of addition of salmeterol to inhaled steroids with doubling of the dose of inhaled steroids. Am J Respir Crit Care Med 1996; 153: $1481-1488$.

5. Pearlman DS, Stricker W, Weinstein W, et al. Inhaled salmeterol and fluticasone: a study comparing monotherapy and combination therapy in asthma. Ann Allergy Asthma Immunol 1999; 82: 257-265.

6. Van Noord JA, Schreurs AJM, Mol SJM, Mulder PG. Addition of salmeterol versus doubling the dose of fluticasone propionate in patients with mild to moderate asthma. Thorax 1999; 54: 207-212.

7. Weersink EJ, Douma RR, Postma DS, Koeter GH. Fluticasone propionate, salmeterol xinafoate, and their combination in the treatment of nocturnal asthma. Am J Respir Crit Care Med 1997; 155: $1241-1246$.

8. Pauwels RA, Lofdahl C-G, Postma DS, et al. Effect of inhaled formoterol and budesonide on exacerbations of asthma. N Engl J Med 1997; 337: 1405-1411.

9. Taylor DR, Town GI, Herbison GP, et al. Asthma control during long-term treatment with regular inhaled salbutamol and salmeterol. Thorax 1998; 53: $744-752$.

10. Sears MR, Taylor DR. The $\beta_{2}$-agonist controversy. Observations, explanations and relationship to asthma epidemiology. Drug Safety 1994; 11: 259-283.

11. Ramage L, Lipworth BJ, Ingram CG, Cree IA, Dhillon DP. Reduced protection against exercise induced bronchoconstriction after chronic dosing with salmeterol. Resp Med 1994; 88: 363-368.

12. Cheung D, Timmers MC, Zwinderman AH, Bel EH, Dijkman JH, Sterk PJ. Long-term effects of a longacting $\beta_{2}$-adrenoceptor agonist, salmeterol, on airway hyper-responsiveness in patients with mild asthma. $N$ Engl J Med 1992; 327: 1198-1203.

13. Drotar DE, Davis EE, Cockcroft DW. Tolerance to the bronchoprotective effect of salmeterol 12 hours after starting twice daily treatment. Ann Allergy Asthma Immunol 1998; 80: 31-34.

14. Yates DH, Kharitonov SA, Barnes PJ. An inhaled glucocorticoid does not prevent tolerance to the bronchoprotective effect of a long-acting inhaled $\beta_{2^{-}}$ agonist. Am J Respir Crit Care Med 1996; 154: 1603 1607.

15. Kalra S, Swystun V, Bhagat R, Cockcroft DW. Inhaled corticosteroids do not prevent the devlopment of tolerance to the bronchoprotective effect of salmeterol. Chest 1996; 109: 953-956.

16. Simons FER, Gerstner TV, Cheang MS. Tolerance to the bronchoprotective effects of salmeterol in adolescents with exercise-induced asthma using concurrent inhaled glucocorticoid treatment. Pediatrics 1997; 99: $655-658$.

17. Booth H, Bish R, Walters J, Whitehead F, Walters EH. Salmeterol tachyphylaxis in steroid treated asthmatics. Thorax 1996; 51: $1100-1104$.

18. Tan KS, Grove A, McLean A, Gnosspelius Y, Hall IP, Lipworth BJ. Systemic corticosteroid rapidly reverses bronchodilator subsensitivity induced by formoterol in asthmatic patients. Am J Respir Crit Care Med 1997; 156: $28-35$.

19. Pansegrouw DF, Weich DJV, LeRoux FPJ. Betaadrenergic receptor tachyphylaxis in acute severe asthma. S Afr Med J 1991; 80: 229-230.

20. Grove A, Lipworth BJ. Effects of prior treatment with salmeterol and formoterol on airway and systemic $\beta_{2}$ responses to fenoterol. Thorax 1996; 51: 585-589.

21. Arledge TE, Liddle R, Stahl E, Rossing TH. Salmeterol does not cause tolerance during longterm asthma therapy. J Allergy Clin Immunol 1996; 98 : 1116-1119.

22. Langley SJ, Masterson CM, Batty EP, Woodcock A. Bronchodilator response to salbutamol after chronic dosing with salmeterol or placebo. Eur Respir J 1998; 11: $1081-1085$.

23. Aziz I, Hall IP, McFarlane LC, Lipworth BJ. $\beta_{2^{-}}$ Adrenoceptor regulation and bronchodilator sensitivity after regular treatment with formoterol in subjects with stable asthma. J Allergy Clin Immunol 1998; 101: 337-341.

24. Nelson HS, Berkowitz RB, Tinkelman DA, Emmett AH, Rickard KA, Yancey SW. Lack of subsensitivity to salbutamol after treatment with salmeterol in 
patients with asthma. Am J Respir Crit Care Med 1999; 159: $1556-1561$.

25. Grove A, Lipworth BJ. Bronchodilator subsensitivity to salbutamol after twice daily salmeterol in asthmatic patients. Lancet 1995; 346: $201-206$.

26. Newnham DM, Grove A, McDevitt DG, Lipworth BJ. Subsensitivity of bronchodilator and systemic $\beta_{2^{-}}$ adrenoceptor responses after regular twice daily treatment with formoterol dry powder in asthmatic patients. Thorax 1995; 50: 497-504.

27. Hancox RJ, Aldridge RE, Cowan JA, et al. Tolerance to beta-agonists during acute bronchoconstriction. Eur Respir J 1999; 14: 283-287.

28. Yan K, Salome C, Woolcock AJ. Rapid method for measurement of bronchial responsiveness. Thorax 1983; 38: $760-765$.

29. American Thoracic Society. 1994. Standardization of
Spirometry: 1994 update. Am J Respir Crit Care Med 1995; 152: $1107-1136$.

30. Johnson M. The beta-adrenoceptor. Am J Resp Crit Care Med 1998; 158: S146-153.

31. Aziz I, Lipworth BJ. In vivo effect of albuterol on methacholine-contracted bronchi in conjunction with salmeterol and formoterol. J Allergy Clin Immunol 1999; 103: 816-822.

32. Tattersfield AE, Postma DS, Barnes PJ, et al. Exacerbations of asthma: a descriptive study of 425 severe exacerbations. The FACET International Study Group. Am J Respir Crit Care Med 1999; 160: $594-$ 599.

33. Korosec M, Novak RD, Myers E, Skowronski M, McFadden ER. Salmeterol does not compromise the bronchodilator response to salbutamol during acute episodes of asthma. Am J Med 1999; 107: 209-213. 